Article

\title{
Infrastructure Operation Efficiency and Influential Factors in Developing Countries: Evidence from China
}

\author{
Xiao Wei ${ }^{1, * \mathbb{D}}$, Haicheng $\mathrm{Xu}^{2}$, Beiqi Zhang ${ }^{1}$ and Jianlong $\mathrm{Li}^{1}$ \\ 1 School of Economics and Management, Chang'an University, Xi'an 710064, China; \\ 2017123065@chd.edu.cn (B.Z.); 18893464460@163.com (J.L.) \\ 2 Research Center of Economics and Management for Highway Infrastructure, School of Economics and \\ Management, Chang'an University, Xi'an 710064, China; jgxy_2@chd.edu.cn \\ * Correspondence: weixiao@chd.edu.cn; Tel.: +86-029-8233-4848
}

Received: 27 November 2018; Accepted: 23 January 2019; Published: 27 January 2019

\begin{abstract}
The development of sustainable infrastructure has been identified as one of the seventeen sustainable development goals by the United Nations. Keeping the operation of infrastructure sustainable in terms of economy becomes a major challenge in developing countries. The objective of this research is to evaluate the operation efficiency of the expressway and explore the key influential factors. This research took expressway mileage as the physical output and evaluated the operation efficiency of the expressway companies based on the super-efficiency Slacks-Based Measure (SBM) model; additionally, we analyzed the influential factors on the basis of the fixed-effects regression model. The results showed the following: (1) The average value of operation efficiency of China's expressway companies from 2007 to 2017 was 0.904 . In general, the operation of expressways was efficient. However, the differences in operation efficiency among the eleven expressway companies were significant, and some companies were seriously inefficient. (2) The asset-liability ratio, the scale, and the structure of property rights in the companies were shown to be the main factors affecting the operation efficiency. These results indicate that the development of innovative financing modes and optimization of the scale of each company are the key directions for infrastructure reform, which could eventually narrow the differences in operation efficiency and allow the development of sustainable infrastructure.
\end{abstract}

Keywords: infrastructure; operation efficiency; super-efficiency SBM model; debt-financed

\section{Introduction}

Building green, ecological, and sustainable development infrastructure has become a heavily researched topic worldwide. The 2030 Agenda for Sustainable Development held at the United Nations Summit in September 2015 identified developing sustainable infrastructure as one of the seventeen development goals for all nations over the next 15 years, along with developing sustainable infrastructure with a focus on affordable and equitable access for all [1]. The Group of Twenty (G20) Summit in 2015 and 2016 also listed infrastructure as a key field of sustainable development for all countries. Once infrastructure is built, it is critical to keep the operation stage sustainable in terms of the economy. Sustainable operation of infrastructure can obtain a positive risk-adjusted return and meanwhile, provide quality, reliable services for society and promote high-quality economic development in the long run.

The operation and management of infrastructure have been the concern of an increasing number of scholars. Wang et al. identified the emerging trends of the impacts of transportation infrastructure on sustainable development based on a scientometric review; they found that cost overrun and 
performance of infrastructure have been the key issues in recent years [2]. Collier et al. emphasized that the cost of infrastructure investments in poor countries should be highly regarded [3]. Hulten pointed out that low- and middle-income countries are paying a growth penalty, over one-quarter of the differential growth rate between these regions and developed countries can be attributed to the difference in the effective use of infrastructural resources [4]. Helm et al. pointed out that infrastructure is underprovided and badly managed [5]. Ansar et al. stated that poor governance of infrastructure investment has led to serious economic and financial fragility in China [6]. Qin et al. argued that the major question of China's infrastructure industry has changed from insufficient supply to improved supply quality and efficiency [7]. Zheng et al. were also concerned with the sustainability performance of infrastructure [8].

China's expressway infrastructure is an appropriate study case. The scale of the expressway in China is the biggest in the world, and $97.14 \%$ of the expressways are toll roads. The study of expressway operation efficiency and influential factors in China would provide a good reference for other developing countries. China's expressway had reached 136.500 kilometers by the end of 2017 [9]. The rapid development of expressways has made a big contribution to China's response to the east Asian and global financial crisis. However, due to the limited financial capacity of the Chinese government, a large percentage of expressway construction was debt-financed, and the rapid development of expressway has result in the build-up of debt. As shown in the 2017 China Toll Road Statistical Bulletin, the accumulated debt balance of the expressway was 4.986 .738 billion yuan, $87.05 \%$ of which consisted of bank loans. Worse still, the gap between income and expenditure of China's expressways in the operation stage is increasing year by year (as shown in Figure 1). In 2017, the annual toll income was 475.275 billion yuan, and the annual total expenditure was 852.375 billion yuan, with a gap of 377.099 billion yuan [10]. China's expressways are facing a serious challenge to sustainable operation.

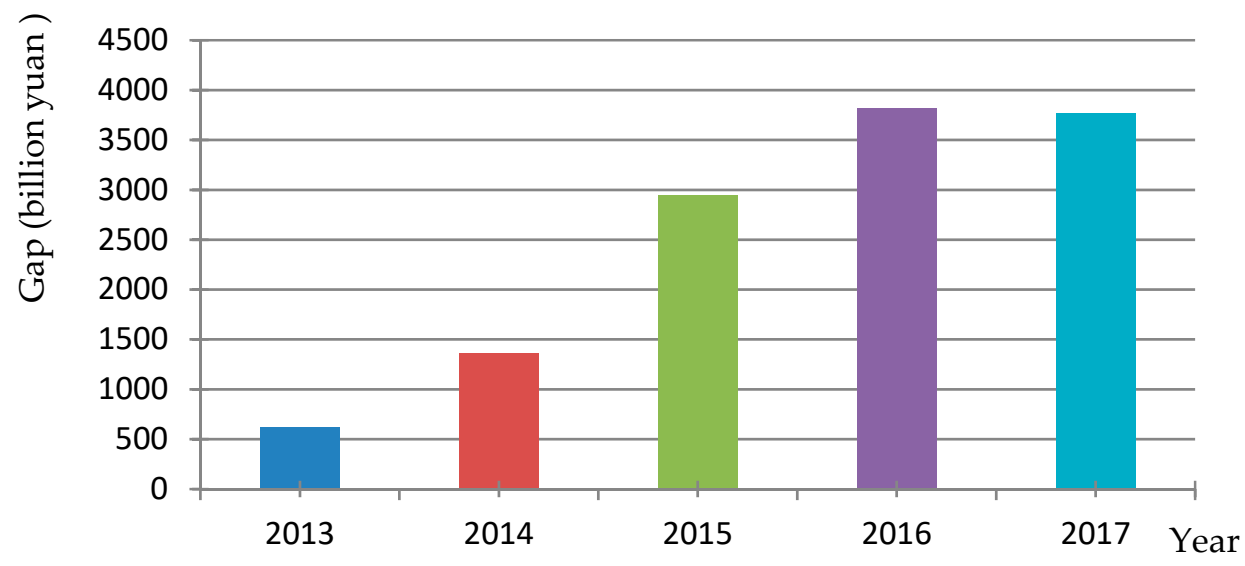

Figure 1. The gap between income and expenditure of China's expressways.

The objective of this research was to evaluate the operation efficiency of the expressways in China on the basis of input-output in the operation stage. In addition, some vital influential factors were tested to identify the constraints that are affecting the expressway's operation efficiency in China. The contributions to the body of knowledge are as follows: (1) The super-efficiency Slacks-Based Measure (SBM) model was adopted to evaluate the operation efficiency of the expressway companies. This method can deal with the input excesses and the output shortfalls as well as distinguishing the efficient decision-making unit (DMU). Therefore, the results are more accurate. (2) We used expressway mileage as an output. This variable can isolate the impacts of the exterior factors of the company on operation efficiency, such as the location of the expressway, the level of local economic development, the population density, and the industry structure. (3) With the aim of identifying the key factors influencing operation efficiency, this research considered the effects of capital structure, the degree of 
market competition, property right structure, and the scale. This research will be beneficial to propose some suggestions to improve the operation efficiency.

The rest of this paper is organized as follows: Section 2 presents a systematic review of research that evaluates the operation efficiency and identifies the influential factors of infrastructure operation efficiency. This section aims to justify our selection of the super-efficiency SBM model, the inputs and outputs for operation efficiency measurement, and the factors affecting operation efficiency. Section 3 briefly introduces the model of super-efficiency SBM, the main inputs and outputs during the expressway operation stage, and the influential factors that may affect efficiency. The data sources of all indicators are also included in Section 3. Section 4 displays the results of the efficiency calculation and the regression outcome. Section 5 discusses the results. The final section presents the study's conclusions and several policy implications for improving the infrastructure operation efficiency in developing countries.

\section{Literature Review}

The quantitative evaluation of the expressways' operation efficiency is necessary to objectively understand the present situation of expressway operation in China. Most of the existing literature calculated expressway operation efficiency based on the input-output theory; the main differences lay in the selection of research samples and outputs. Some scholars researched the toll road industry, for example, Xu et al. used the data of the Toll Road Industry Statistical Bulletin from 2014 to 2015 and took toll income as the output, then measured the expressway operation efficiency at the industry level using the three-stage Data Envelopment Analysis (DEA) model, and the result was 0.717 [11]. Bai et al. adopted a back propagation (BP) neural network method to calculate the average provincial industrial resource allocation efficiency based on the similar inputs and outputs and the same data, they concluded that the allocation efficiency of the expressway was 83.4\% [12]. Wang et al. took the companies mainly engaged in expressway toll collection as research samples to estimate the comprehensive technical efficiency of expressway companies with toll income, total asset returns, and earnings per share as the outputs; the result calculated by the nonparametric Data Envelopment Analysis (DEA) model in 2013 was 0.89 [13]. It can be seen that, although the results of efficiency values were different, a largely consistent conclusion was reached in that the operation efficiency of the expressways is not ideal.

Identifying the factors influencing operation efficiency is also important. Because of the natural monopolistic nature of expressways, many scholars have mainly focused on the effects of monopoly and government management institution on efficiency. China's expressways are divided by provincial administrative boundaries. The provincial government is in charge of the management and operation rights of all expressways within the province. Generally, the expressways are operated by the state-owned financing platform company or by other companies, and the latter are granted operation rights for a certain period of time by the government through investment in the construction of expressways or the transfer of franchise rights. Because of the high barriers of private capital access to infrastructure, a large percentage of the expressways are controlled by the government [14]. Bai et al. qualitatively analyzed the efficiency of the expressway industry and then put forward that the loss of allocation efficiency should be attributed to government rent-seeking [12]. Zhu measured the industry's efficiency and the degree of administrative monopoly of China's toll roads; the results of their regression show that administrative monopoly has a negative effect on industry efficiency [15]. Xu et al. used government toll roads as an explanatory variable to analyze the industry's overall operation efficiency. The results indicated that the proportion of government toll roads has a significantly negative effect on the industry's overall efficiency; they concluded that the cause leading to inefficient operation is the excessive intervention of the government [11]. Considering the characteristics of the expressway industry, Pang et al. empirically demonstrated that the location and scale of the companies dictated their cost efficiency [16].

In summary, the contributions of this study were established from three aspects: 
First, most of the existing research on the infrastructure operation efficiency used the DEA model $[11,13,16]$. Although the DEA model has been widely used in the fields of performance evaluation and decision-making, because the DEA model is a nonparametric production frontier model, there is no need to preset the form of the production function. The traditional DEA models are based on radial variables, and the magnitude of quasi-fixed inputs and/or outputs are temporarily constrained. This approach cannot take the slack in inputs and outputs into account, so the measurement of efficiency values is not accurate enough [17]. Tone considered the above defects and put the slack variables into the objective function directly, and then proposed a non-radial, non-angle SBM model [18]. In addition, the super-efficiency SBM model was also established to further distinguish the efficiency of DMUs [19]. This measure was determined only by consulting the reference set of the DMU and was not affected by the statistics of the whole data set. Some scholars applied the SBM model and super-efficiency SBM model to the efficiency calculation in other fields [20-22]. Therefore, the super-efficiency SBM model was adopted to evaluate the operation efficiency of the expressway companies.

Second, taking the toll income of expressways as the output may cause deviations in calculating the expressway operation efficiency. As is well-known, toll income is mainly decided by traffic flow. Moreover, traffic generally depends on external environmental factors, such as the location of the expressway, the level of local economic development, the population density, and the industry structure. That said, a higher toll income may not be the result of effective operation. Referring to Xi et al. regarding the mileage of public infrastructure as the output to measure the investment efficiency of infrastructure [23]. Ouyang et al. also proposed that the efficiency measured by capital output has an overestimation bias when measuring the supply efficiency of infrastructure and that the efficiency measured by physical output is more accurate [24]. Consequently, this study took expressway mileage as the output.

Third, too much attention has been paid to government rent-seeking and the lack of subjective enthusiasm generated by companies to improve the operation efficiency, ignoring some objective difficulties that exist in the expressway operation. It is obvious that huge debt forced some operation companies to spend a large part of their expenditure to repay the principal and interest. Actually, all these factors were included in this study.

\section{Methods and Data}

\subsection{Super-Efficiency SBM Model}

This study adopted the super-efficiency SBM model to measure the operation efficiency of the expressway companies. The super-efficiency SBM directly accounts for input excesses and output shortfalls of the DMU. The output-oriented super-efficiency SBM model is appropriate because there are zeros in the input data in this study. According to Cheng, G., the output-oriented model allows zeros to occur in the input data, and this is not allowed in input-oriented model [25]. We assumed that there were $n$ DMUs, each company had $m$ inputs and $s$ outputs, and that the expressway company followed constant returns-to-scale (CRS). The input and output matrices were $X=\left(x_{i j}\right) \in R^{m \times n}$ and $Y=\left(y_{i j}\right) \in R^{s \times n}$, respectively. Finally, as shown in Formula (1), the output-oriented CRS SBM model was constructed by referring to the basic SBM model proposed by Tone [18].

$$
\begin{gathered}
\rho^{*}=\min \rho=\frac{1}{1+\frac{1}{q} \sum_{r=1}^{q} s_{r}^{+} / y_{r k}} \\
\sum_{j=1}^{n} x_{i j} \lambda_{j} \leq x_{k} \\
\text { s.t. } \quad \sum_{j=1}^{n} y_{r j} \lambda_{j}-s^{+}=y_{k} \\
\lambda, s^{+} \geq 0 \\
r=1,2, \cdots, q ; i=1,2, \cdots, m ; j=1,2, \cdots, n
\end{gathered}
$$


where $\rho$ is the efficiency value. The vectors $x$ and $y$ indicate the inputs and outputs. The $s^{+}$vectors stand for the output shortfall and are called slacks. $\lambda$ is the weight vector; $i$ is the input number, $r$ is the output number; $m$ and $s$ indicate the total amount of inputs and outputs. When $s^{+*}=0$, it means that there are no output shortfalls; thus, the DMU is SBM-efficient. Then, for the efficient DMU of SBM, its output-oriented super-efficiency CRS SBM model is shown in Formula (2):

$$
\begin{array}{cc}
\rho_{S E}^{*}= & \min \rho_{S E}=\frac{1}{1-\frac{1}{s} \sum_{r=1}^{s} s_{r}^{+} / y_{r k}} \\
& \sum_{j=1, j \neq k}^{n} x_{i j} \lambda_{j} \leq x_{i k} \\
\text { s.t. } \quad & \sum_{j=1, j \neq k}^{n} y_{r j} \lambda_{j}+s_{r}^{+} \geq y_{r k} \\
\lambda, s^{-}, s^{+} \geq 0 & \\
r=1,2, \cdots, q ; i=1,2, \cdots, m ; j=1,2, \cdots, n(j \neq k)
\end{array}
$$

The operation efficiency in this research was calculated according to Formulas (1) and (2), and the final operation efficiency is expressed as shown in Formula (3):

$$
\text { Efficiency }=\left\{\begin{array}{l}
\rho^{*}\left(\rho^{*}<1\right) \\
\rho_{S E}^{*}\left(\rho^{*}=1\right)
\end{array} .\right.
$$

\subsection{Variable Selection}

\subsubsection{Selection of Inputs and Outputs for Operation Efficiency Measurement}

This research focused on the operation stage of the expressway and fully considered the characteristics of the expressway industry. We selected the following inputs and outputs from the perspective of the combination of the production factors of capital, labor, and technology.

1. Output Expressway mileage operated by expressway companies.

2. Inputs The main business cost is the direct input cost, generated during the process of providing the vehicle access service. It includes the cost of the toll collection equipment, the cost of maintenance business, the depreciation of road production, the road administration expenditure, etc. This cost is the largest reduction in the profit and loss account. Thus, when the output is certain, the key to improving the efficiency is to control the cost of the main business effectively.

Salary is an indicator that measures the input and remuneration of employees in expressway companies. The number of employees and their salaries in state-owned companies are important input items to which many researchers pay close attention. Due to the high proportion of state-owned property rights in the expressway industry [26], salary is an important indicator of labor input.

Interest expense is an important component of the cost of expressway companies. Expressway industry is capital-intensive. At present, the scale of China's expressway continues to expand, and the acquisition of expressway franchises or the construction of expressways by government departments requires a huge amount of capital investment. However, the speed of capital recovery during operation is slow, and the operation period is generally 30 years or even longer. Debt financing, such as bank loans, is one of the most important capital sources for expressway companies, so interest expenses are an indispensable indicator of capital input.

Management expenses include personnel expenses, office expenses, depreciation and amortization, travel expenses, and taxes. Management expenses are an important indicator for measuring the efficiency of expressway company management.

Total assets include the sum of circulating assets, fixed assets, and intangible assets owned by expressway operation companies. Total assets reflect the resource allocation and application of expressway companies. This variable is crucial to reflect the development capability of companies. 
The list of outputs and inputs is shown as Table 1.

Table 1. List of outputs and inputs.

\begin{tabular}{ccc}
\hline Variables & Indicator & Data Source \\
\hline Output & Expressway Mileage Operated by Expressway Companies & Companies' Annual Reports \\
\hline \multirow{3}{*}{ Inputs } & The Main Business Cost & Wind Database \\
& Salary & Wind Database \\
& Interest Expense & Wind Database \\
& Management Expenses & Wind Database \\
& Total Assets & Wind Database \\
\hline
\end{tabular}

3.2.2. Selection of Factors Affecting Operation Efficiency

This study considered the following factors that may affect the expressway operation efficiency:

1. The asset-liability ratio reflects the capital structure of companies. Due to the debt incurred by the construction link, the repayment of principal and interest becomes a relatively large expenditure burden. De-leveraging is regarded as the primary and core task of supply-side reform in the transportation sector [27]. The expressway industry is capital intensive. Debt financing, such as bank loans, is an important capital source for expressway companies. On the one hand, debt financing can improve the corporate governance structure and play a positive role in governance. On the other hand, too much debt will increase the burden of the company. This paper used the proportion of liabilities to total assets to calculate the asset-liability ratio.

Hypothesis 1. The asset-liability ratio of the expressway companies is negatively correlated with the operation efficiency.

2. The degree of market competition. According to the theory of industrial organization, market competition is undoubtedly crucial for market performance. Wang, $\mathrm{J}$ et al. researched the reformation of infrastructure in many countries and concluded that the introduction of competition in the telecommunications industry in America has achieved great success [28]. As for the expressway industry, the competition faced by expressway companies mainly comes from getting the franchise before the expressway companies enter the operation market and other modes of transportation during operation. Expressways are all built according to the planning of the road network. Generally, there is no parallel road; consequently, there is no competition relationship between two companies operating different expressways. That is, once the expressway operation company obtains the franchise of the expressway, the company will operate in a monopolized way. During this process, the competition faced by expressway companies mainly comes from other modes of transport. In particular, the high-speed railway has brought great convenience to the city traffic and has a certain influence on expressways. Since the competition of the franchise cannot be measured in detail, this paper used railway density as an agent variable to represent the influence of market competition on the operation efficiency.

Hypothesis 2. The degree of market competition is positively correlated with the operation efficiency.

3. The level of regional economic development. We assumed that the level of economic development affects the operation efficiency by affecting the management philosophy and technical level of the expressway company. Regions with more developed economies, stronger entrepreneurial management ability and more advanced technology will be adopted by enterprises. At the same time, these companies will have a more perfect external market environment. We used regional gross domestic product (GDP) to indicate the level of regional economic development. 
Hypothesis 3. The level of regional economic development is positively correlated with the operation efficiency.

4. Scale. The expressway industry has a significant scale effect, and scale expansion is one of the most important ways to improve the efficiency of industry [17]. We selected the expressway mileage operated by expressway companies as the agent variable and assumed that the more expressways the company operates, the higher the efficiency.

Hypothesis 4. The scale of the expressway companies is positively correlated with the operation efficiency.

5. The structure of property rights. Mixed ownership reform is becoming an important measure to improve performance. It is expected that private property rights would stimulate the incentive mechanism. This paper used the sum of the proportion of state-owned shares and state-owned legal person shares in the top ten shareholders of the companies to indicate the structure of property rights.

Hypothesis 5. The structure of property rights of the expressway companies is negatively correlated with the operation efficiency.

All of above the factors affecting the operation efficiency are shown as Table 2.

Table 2. Definitions of factors and data sources.

\begin{tabular}{cccc}
\hline Factor & Indicator & Symbol & Data Source \\
\hline Capital Structure & Asset-Liability Ratio & Capital & Companies' Annual Reports \\
\hline Market Competition & Railway Density & Market & Wind Database \\
\hline Scale & GDP & GDP & Wind Database \\
\hline Property Rights Structure & $\begin{array}{c}\text { Expressway Mileage Operated by Expressway } \\
\text { Companies }\end{array}$ & Scale & Companies' Annual Reports \\
& $\begin{array}{c}\text { The Sum of the Proportion of State-Owned Shares } \\
\text { and State-Owned Legal Person Shares in the Top Ten } \\
\text { Shareholders of the Companies }\end{array}$ & State & Companies' Annual Reports \\
\hline
\end{tabular}

\subsection{Data Collection}

This paper took the listed expressway companies as research samples. By the end of 2017, there were 17 listed expressway companies in China, excluding those companies whose main business was not expressway toll collection. Finally, the selected companies were the following: Jiangsu Expressway, Shandong Hi-Speed, Ganyue Expressway, Zhongyuan Expressway, Xiandai Investment, Anhui Expressway, Fujian Expressway, Shenzhen Expressway, Chutian Expressway, Dongguan Development, and Wuzhou Communications. This research collected data from 2007 to 2017. All the data sources of the indicators are listed in Tables 1 and 2. The per capital regional GDP was adjusted based on 2007 values, as data for the density of railways could only be obtained from 2007 to 2016 . The statistical descriptions of the influential factors are shown in Table 3.

Table 3. Descriptive statistics of variables.

\begin{tabular}{cccccc}
\hline Variables & Sample & Average & Standard Error & Minimum & Maximum \\
\hline Capital & 121 & 47.539 & 16.103 & 16.490 & 80.230 \\
Market & 110 & 0.021 & 0.006 & 0.012 & 0.035 \\
GDP & 121 & $28,089.360$ & $18,713.190$ & 5800.250 & $75,130.160$ \\
Scale & 121 & 541.183 & 405.496 & 55.700 & 2137.000 \\
State & 121 & 55.396 & 15.102 & 6.840 & 87.230 \\
\hline
\end{tabular}




\section{Results}

\subsection{Results of Efficiency Calculation}

Based on the above input and output data, we calculated the operation efficiency of 11 expressway companies using MaxDEA Ultra 7.0 (Beijing Realworld Software Company, Beijing, China) software. In the first step, we just adopted the output-oriented CRS SBM model; the results during this phase were consistent with our hypothesis that there are many efficient DMUs, for example, Shandong Hi-Speed, Fujian Expressway, Chutian Expressway, and Wuzhou Communications. It also confirmed that the super-efficiency SBM model is necessary in this research. Consequently, we reported the results calculated through the output-oriented super-efficiency CRS SBM model. Table 4 shows the results of the expressway operation efficiency. The average value of each expressway company from 2007 to 2017 is shown as Figure 2. Additionally, changing trends in the operation efficiency of the eleven expressway companies can be seen in Figure 3.

Table 4. Results of the efficiency calculation, 2007-2017.

\begin{tabular}{ccccccccccccc}
\hline Company & $\mathbf{2 0 0 7}$ & $\mathbf{2 0 0 8}$ & $\mathbf{2 0 0 9}$ & $\mathbf{2 0 1 0}$ & $\mathbf{2 0 1 1}$ & $\mathbf{2 0 1 2}$ & $\mathbf{2 0 1 3}$ & $\mathbf{2 0 1 4}$ & $\mathbf{2 0 1 5}$ & $\mathbf{2 0 1 6}$ & $\mathbf{2 0 1 7}$ & Average \\
\hline Jiangsu & 0.417 & 0.420 & 0.427 & 0.495 & 0.574 & 0.845 & 0.796 & 0.907 & 0.554 & 0.646 & 0.638 & 0.611 \\
Shandong & 0.405 & 0.460 & 0.545 & 2.174 & 1.754 & 1.386 & 1.589 & 1.507 & 1.456 & 1.091 & 1.372 & 1.249 \\
Ganyue & 0.616 & 0.491 & 0.510 & 0.637 & 0.533 & 0.774 & 0.613 & 0.626 & 0.552 & 0.629 & 0.685 & 0.606 \\
Zhongyuan & 0.585 & 0.540 & 0.480 & 0.478 & 0.503 & 0.742 & 0.632 & 1.090 & 1.089 & 1.288 & 1.750 & 0.834 \\
Xiandai & 0.625 & 0.522 & 0.630 & 0.498 & 0.722 & 0.944 & 0.621 & 0.423 & 0.382 & 0.330 & 0.350 & 0.550 \\
Anhui & 0.525 & 0.600 & 0.748 & 0.687 & 0.907 & 1.019 & 0.928 & 0.998 & 1.221 & 1.508 & 1.462 & 0.964 \\
Fujian & 0.518 & 0.543 & 0.653 & 1.127 & 1.182 & 0.823 & 0.959 & 1.106 & 1.129 & 1.235 & 0.630 & 0.901 \\
Shenzhen & 0.800 & 0.794 & 0.764 & 0.643 & 0.476 & 0.554 & 0.552 & 0.611 & 0.432 & 0.424 & 0.480 & 0.594 \\
Chutian & 1.398 & 3.963 & 1.922 & 1.414 & 1.661 & 1.604 & 1.645 & 1.318 & 1.231 & 1.202 & 0.938 & 1.663 \\
Dongguan & 0.209 & 0.245 & 0.252 & 0.250 & 0.259 & 0.299 & 0.282 & 0.297 & 0.230 & 0.292 & 0.888 & 0.318 \\
Wuzhou & 3.133 & 3.085 & 3.028 & 1.985 & 0.777 & 1.127 & 0.905 & 0.903 & 0.882 & 1.237 & 1.119 & 1.653 \\
Average & 0.839 & 1.060 & 0.905 & 0.944 & 0.850 & 0.920 & 0.866 & 0.889 & 0.832 & 0.899 & 0.938 & 0.904 \\
\hline
\end{tabular}

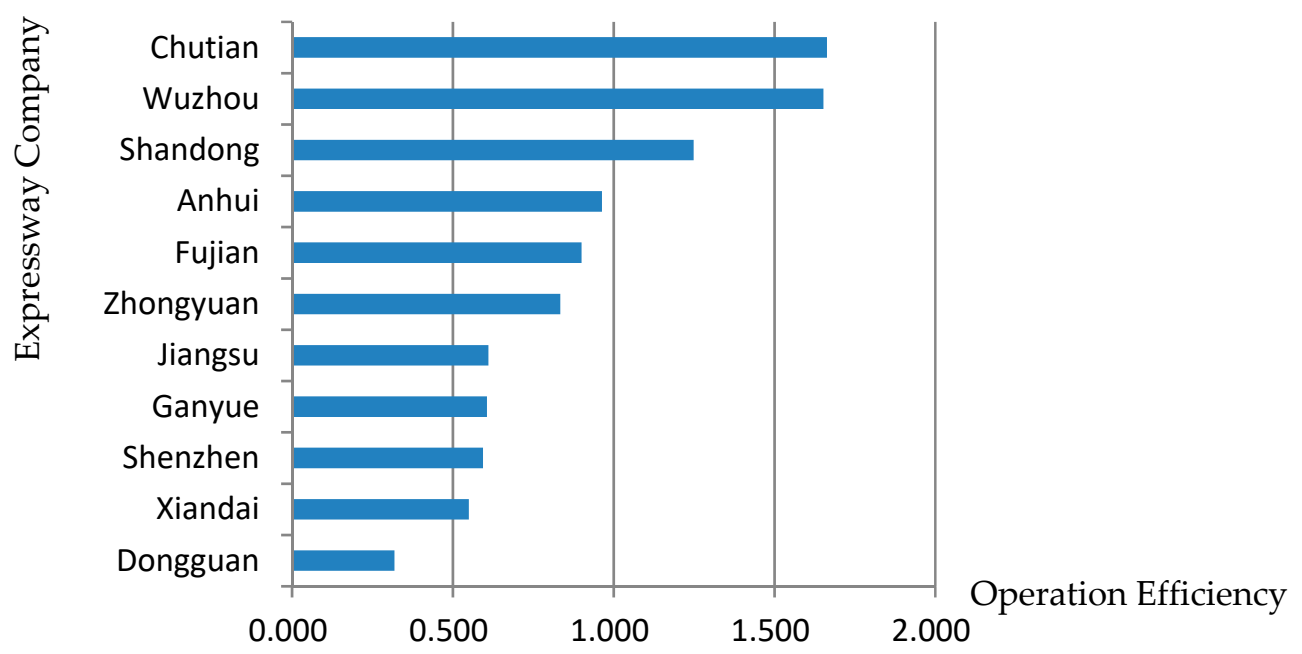

Figure 2. The average value of each expressway company from 2007 to 2017. 


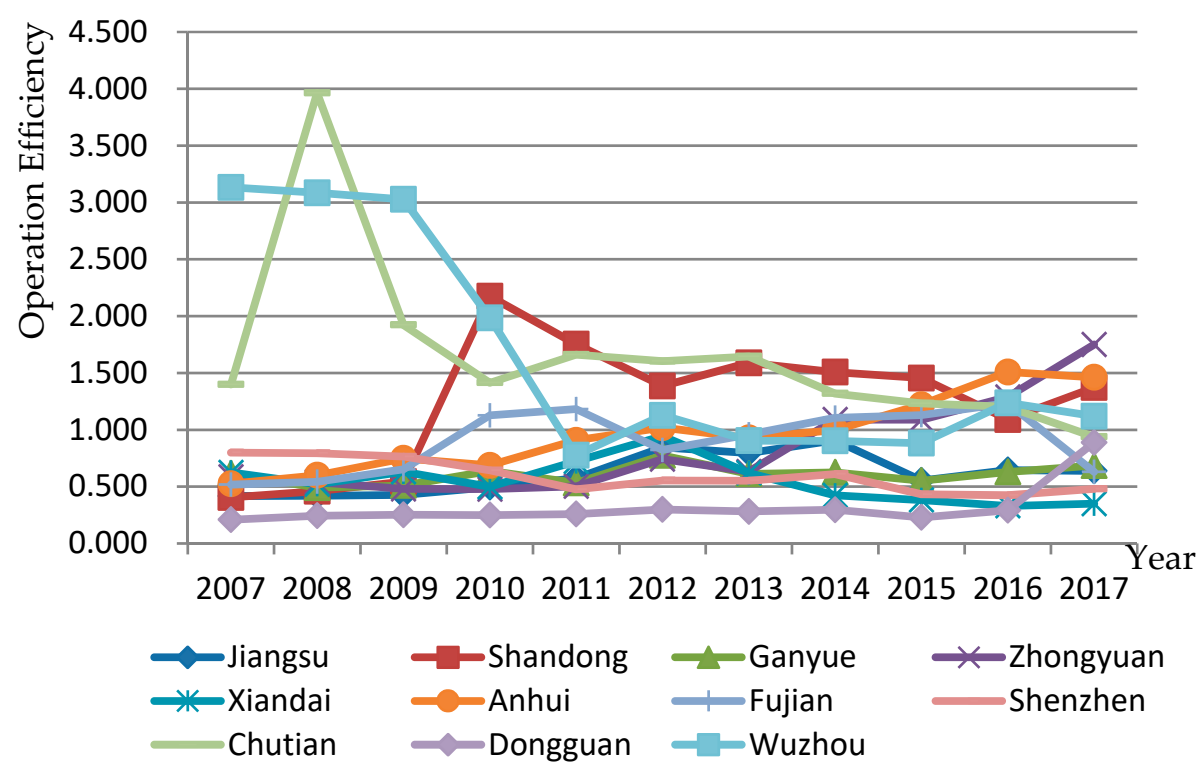

Figure 3. Changing trends in operation efficiency of the eleven expressway companies.

On average, in general, the operation of the expressways is efficient. Table 4 indicates that the average value of all expressway companies from 2007 to 2017 was 0.904 . However, a more careful analysis, shown in Figure 2, reveals that the differences between expressway companies are significant. Only three expressway companies were shown to be efficient, and the others were shown to be inefficient. In detail, the efficient expressway companies were Chutian Expressway, Wuzhou Communications, and Shandong Hi-Speed. The values of operation efficiency in the top three companies were more than 1000 in almost every year. The operation efficiency of next three expressway companies, the Anhui Expressway, Fujian Expressway, and Zhongyuan Expressway, followed with average values of $0.964,0.901$, and 0.834 . The average value of four expressway companies was between 0.550 and 0.611; these expressway companies included Jiangsu Expressway, Ganyue Expressway, Shenzhen Expressway, and Xiandai Investment. Moreover, considerable attention must be paid to Dongguan Development, and its value of operation efficiency was just 0.318 .

Analyzing the changing trends oin operation efficiency of the eleven expressway companies could allow us to explore the influential factors. As shown in Figure 3, on the whole, the changing trend was steady for the majority of expressway companies. Nevertheless, before the point of 2010, the trends of operation efficiency of Chutian Expressway, Wuzhou Communications, and Shandong Hi-Speed had big fluctuations. From 2010 to 2017, the top three expressway companies also maintained an efficient situation. The operation efficiency of Anhui Expressway, Fujian Expressway, and Zhongyuan Expressway was gradually increasing. On the contrary, the operation efficiency of Shenzhen Expressway and Xiandai Investment decreased year-by-year. The expressway companies Jiangsu Expressway and Ganyue Expressway showed no significant trend. In 2017, the value of operation efficiency of Dongguan Development reached 0.888 unpredictably, although it never exceeded 0.300 from 2010 to 2016.

\subsection{Results of the Fixed-Effects Regression}

On the basis of operation efficiency calculated by the super-efficiency SBM model, the influential factors can be analyzed using a regression model. In the regression model used in this study, the operation efficiency was the dependent variable, and the possible influential factors were independent variables. As Cheng, G. said, the efficiency data calculated by the super-efficiency SBM model is not truncated data [25]. Consequently, there is no need to employ the Tobit regression model. In order 
to control the individual effects, we can adopt the fixed-effects model or the random-effects model. Formula (4) represents the regression expression.

$$
\text { Efficiency }_{i t}=\beta_{0}+\beta_{1} \text { Capital }_{i t}+\beta_{2} \text { Market }_{i t}+\beta_{3} G D P_{i t}+\beta_{4} \text { Scale }_{i t}+\beta_{5} \text { State }_{i t}+\mu_{i}+\varepsilon_{i t}
$$

where $\beta_{0}$ denotes a constant; $\beta_{1}, \beta_{2}, \beta_{3}, \beta_{4}$, and $\beta_{5}$ denote the parameters of the independent variables; $\mu_{i}$ represents the individual effects; and $\varepsilon_{i t}$ represents the random error term.

In this research, we used the Hausman test in the first step. The $p$-value was 0.0013; this result indicates that we should reject the null hypothesis that $\mu_{i}$ is uncorrelated with the independent variables. As a result, the effects of possible influential factors on the expressway operation efficiency were analyzed by using the fixed-effects regression model. This model was performed with Stata 12 (StataCorp LLC, College Station, TX, USA) software. The results of the fixed-effects regression are shown as Table 5.

Table 5. Regression results.

\begin{tabular}{ccccc}
\hline Variable & Coefficient & Standard Error & $\mathbf{t}$ & $p$ \\
\hline Capital & $-0.0277407^{* * *}$ & 0.0035922 & -7.72 & 0.000 \\
Market & $3.55675^{* 6}$ & 19.51976 & 0.18 & 0.856 \\
GDP & $2.69 \times 10^{-6}$ & $9.40 \times 10^{-6}$ & 0.29 & 0.775 \\
Scale & $0.0008667^{* * *}$ & 0.0002189 & 3.96 & 0.000 \\
State & $0.009363^{*}$ & 0.0051982 & 1.80 & 0.075 \\
Cons & $1.083034^{* * *}$ & 0.4033918 & 2.68 & 0.009 \\
\hline
\end{tabular}

Note: ${ }^{* *} p<0.01,{ }^{* *} p<0.05,{ }^{*} p<0.1$.

In these regression results, we focused on the significance and the sign of the coefficient. It is clear that the capital structure of the expressway companies significantly influenced the operation efficiency. That is, the asset-liability ratio of expressway companies was negatively correlated with the operation efficiency with a significance of $1 \%$. The principal and interest have already become a relatively large expenditure burden for each expressway company. The scale of the expressway companies played an important role in improving the operation efficiency. It indicated that the expressway operation is in the stage of increasing returns to scale. In addition, the structure of property rights was positively correlated with the operation efficiency with a significance level of $10 \%$. The state-owned property rights of the expressway companies can also promote their operation efficiency. However, the degree of market competition and the level of regional economic development had no significant effect on the operation efficiency of expressway companies.

\section{Discussion}

As seen from the above results, the operation of expressway is efficient, on average. Nevertheless, the differences in operation efficiency of the eleven expressway companies were significant. Based on the regression results in Table 5, this section conducted a further analysis from five perspectives.

First, the asset-liability ratio had a significant negative effect on expressway companies' operation efficiency. The average asset-liability ratio of the expressway operation companies in the study sample was $47.539 \%$. Some company debt ratios were too high, for example the asset-liability ratio of Zhongyuan Expressway in 2013 was up to 80.23\%. Zhang, J., on the basis of previous research, concluded that the optimal asset-liability ratio of listed companies is 30\% [29]. Obviously, the debt of expressway companies is too high, and the debt burden is too heavy. The implicit debt problem caused by the toll road industry has attracted the attention of the government and the financial market.

Second, it was shown that market competition has no significant effect on operation efficiency. In contrast to Hypothesis 2, it would seem that the competition from the railway industry only affects the toll income and does not promote an increase in expressway mileage. The improvement of operation efficiency for expressway companies means that it must reduce the cost or expand the scale. To the 
best of our knowledge, the competition among the expressway companies may be effective to improve business efficiency.

Third, the influence of regional economic development on the operation efficiency was not significant, which is consistent with the conclusions of Yang et al. Their study showed that the management cost of state-owned companies is rigid and insensitive to changes at the macroeconomic development level [30]. This result indicates that the level of regional economic development is not a limiting factor for the improvement of company performance. The external economic environment of a company has little effect on the improvement of its internal management efficiency.

Fourth, the scale significantly promoted operation efficiency, consistent with Hypothesis 4. A more careful analysis indicated that the differences in expressway mileage operated by expressway companies can explain their different operation efficiencies to some extent. On average, the value of operation efficiency of Shandong Hi-Speed was 1249 with 1.458 .512 kilometers of expressway from 2007 to 2017. In contrast, the value of operation efficiency of Dongguan Development was just 0.318 under the scale of 58.732 kilometers. This indicates that in this development stage, the expressway operation efficiency was increasing returns to scale. Adjusting the scale of each expressway company would be a good way to improve the operation efficiency.

Fifth, the effect of property right structure on expressway operation efficiency was also significant. Combined with the above analysis, we think that the state-owned property rights contributed to the expansion of expressway mileage operated by expressway companies. Expressway is one kind of important transportation infrastructure, and the government is in charge of its transfer of franchise rights.

\section{Research Conclusions and Policy Implications}

\subsection{Research Conclusions}

This study evaluated the operation efficiency of expressway companies based on the super-efficiency SBM model and identified the top influential factors on the basis of the fixed-effects regression model. The research conclusions were as follows: (1) The average value of operation efficiency in China's expressway companies during the period of 2007 to 2017 was 0.904. In general, the operation of expressways is efficient. However, significant differences in operation efficiency exist among the eleven expressway companies. Some expressway companies with inefficient operation must be paid considerable attention. Moreover, the values of operation efficiency measured by mileage as physical output are more accurate and reliable. This approach isolated the impact of external factors of the company on the operation efficiency, and it contributed to the design of regression research. (2) Identifying the key factors influencing the operation efficiency from the perspective of companies' inner environments was the main purpose of this study. Empirical studies indicated that the asset-liability ratio has a significantly negative effect on expressway companies' operation efficiency, the effect of scale and the property rights structure of the expressway companies is significantly positive, and the degree of market competition and the level of regional economic development have no significant influences. In summary, a high asset-liability ratio and lack of scale effect are the main influential factors that improve the expressway operation efficiency in China. These results indicate that developing innovative financing modes and optimizing the scale of expressway companies are the key directions for infrastructure reform in developing countries.

\subsection{Policy Implications}

The evidence from this study points towards the following policy implications.

First, innovative financing models should be developed to reduce companies' asset-liability ratios. At present, the debt ratio of China's expressway operation companies is too high, and most of the debt consists of bank loans. One of the main reasons for this is that most expressway construction is debt-financed. Therefore, in order to reduce the debt ratio of expressway operation companies, the 
most important measure is innovating the expressway construction financing mode. The government should promote the public-private partnership (PPP) mode, issue special government bonds, set up transportation industry investment funds, and put forward preferential policies to attract private companies and investors. These measures should optimize the capital structure of companies by reducing the early capital investment and existing liabilities.

Second, the scale of each company should be optimized, and regional cooperation should be promoted. As we all know, market segmentation between regions is the main reason that leads to the differences in expressway mileage operated by expressway companies. The provincial government is in charge of the management and operation rights of all expressways within their provinces. Generally, the regional government is unwilling to transfer the operation rights to the expressway companies that own other regions. It is urgent to promote the cooperation within expressway companies located in different regions. Mergers and reorganization are good methods to achieve the optimal size through adjusting the scale of each company.

Third, the institutional environment of the government needs to be improved. As is well-known, compared with developed countries, the disadvantages of developing countries are intense, including a poor institutional environment, unsound laws, and a low degree of marketization. Because of the large investment, long construction period, and slow return speed of the infrastructure industry, the stability and continuity of government institutions are crucial. Learning from the experience of international expressway management, the relevant stakeholders of expressway construction and operation need to establish a legally binding contract. A contract is used to adjust profit and risk, as well as to avoid the occurrence of government default or other problems influencing the return of private capital. Therefore, developing countries should improve the institutional environment and government quality to broaden the infrastructure construction financing channels and eventually realize the sustainable development of infrastructure.

This research contributes to the evaluation of the operation efficiency of China' expressways and the conclusion that using innovative financing modes and adjusting the scale operated by companies ought to be considered in order to develop sustainable infrastructure. The limitation of research is that the sample just included eleven expressway listed companies. This is because we could not get enough data from other companies, especially the state-owned financing platform companies. Expanding the sample size should be done when more datasets are released to the public. In addition, the efficiency of other infrastructures should be considered in future research, such as urban public transport, railways, water supply systems, and so on.

Author Contributions: X.W. and H.X. conceived and designed the paper, X.W. conducted the interviews, analyzed the data, and contributed to drafting the paper. H.X. contributed useful advice and modified the paper. B.Z. and J.L. contributed to the data collection and the final writing review.

Funding: This research was funded by the Fundamental Research for Funds for the Central Universities (No. 300102238502 and No. 300102238639).

Acknowledgments: The authors thank the reviewers of this paper for their constructive comments and suggestions.

Conflicts of Interest: The authors declare no conflict of interest.

\section{References}

1. Transforming Our World: The 2030 Agenda for Sustainable Development. Available online: https://www. fmprc.gov.cn (accessed on 21 July 2018).

2. Wang, L.; Xue, X.; Zhao, Z.; Wang, Z. The impacts of transportation infrastructure on sustainable development: Emerging trends and challenges. Int. J. Environ. Res. Public Health 2018, 15, 1172. [CrossRef] [PubMed]

3. Collier, P.; Kirchberger, M.; Söderbom, M. The Cost of Road Infrastructure in Low- And Middle-Income Countries. World Bank Econ. Rev. 2016, 30, 522-548. [CrossRef] 
4. Hulten, C.R. Infrastructure Capital and Economic Growth: How Well You Use It May Be More Important Than How Much You Have. Nber Working Papers; National Bureau of Economic Research: Cambridge, MA, USA, 1996; pp. 1-37.

5. Helm, D.; Mayer, C. Infrastructure: Why it is under Provided and Badly Managed. Oxf. Rev. Econ. Policy 2016, 32, 343-359. [CrossRef]

6. Ansar, A.; Budzier, A.; Lunn, D. Does Infrastructure Investment Lead to Economic Growth or Economic Fragility? Evidence from China. Oxf. Rev. Econ. Policy 2016, 32, 360-390. [CrossRef]

7. Qin, S.; Rong, C. China's Transportation Infrastructure Supply and Demand Mismatch and Public-Private Cooperation Dilemma and its Countermeasures-Based on the Perspective of Supply-Side Structural Reform. Yunnan Soc. Sci. 2017, 4, 64-69.

8. Zheng, S.Q.; Xu, K.; He, Q.; Fang, S.Z.; Zhang, L. Investigating the sustainability performance of ppp-type infrastructure projects: A case of China. Sustainability 2018, 10, 4162. [CrossRef]

9. The Statistical Bulletin of the Development of the Transportation Industry in 2017. Available online: http: / /zizhan.mot.gov.cn/zfxxgk/bnssj/zhghs/201803/t20180329_3005087.html (accessed on 7 August 2018).

10. National Statistics Summary Table of Toll Road in 2017. Available online: http://zizhan.mot.gov.cn/zfxxgk/ bnssj/glj/201808/t20180824_3062127.html (accessed on 1 September 2018).

11. Xu, H.; Wang, Y.; Jia, R. Research on Efficiency of Toll Road Dual-Track Operation System Based on Three Stage DEA and Tobit Regression Model. China J. Highw. Transp. 2017, 30, 125-132. [CrossRef]

12. Bai, P.; Xu, H. Evaluation on Resource Allocation of Toll-Road Infrastructure Industry in China. Price Theory Pract. 2017, 2, 146-149.

13. Wang, B.; Li, Q. Performance Evaluation and Dynamic Analysis of Listed Companies in the Expressway Industry. Co. Econ. 2014, 175-179. [CrossRef]

14. Wang, J. Study on Optimizing Market Structure for Promoting Economic Performance in Toll-Road Industry. Ph.D. Thesis, Chang'an University, Xi'an, China, 2013.

15. Zhu, Y. Quantitative Analysis of the Administrative Monopoly and Efficiency of Toll Road Industry. Stat. Decis. 2015, 104-107. [CrossRef]

16. Pang, R.; Liu, B.; Wang, T. Location, Firm Scale, Stock Right Structure and Cost Efficiency: Empirical Study on 19 Listed Highway Companies. J. Cent. Univ. Financ. Econ. 2008, 51-56.

17. Yang, G.; Liu, W.; Zheng, H. A Review of Data Envelopment Analysis Methods (DEA). J. Syst. Eng. 2013, 28, 840-860.

18. Tone, K. A Slacks-Based Measure of Efficiency in Data Envelopment Analysis. Eur. J. Oper. Res. 2001, 130, 498-509. [CrossRef]

19. Tone, K. A slacks-based measure of super-efficiency in data envelopment analysis. Eur. J. Oper. Res. 2002, 143, 32-41. [CrossRef]

20. Jin, G.; Shen, K. Revaluation and Deconstruction of Technical Efficiency in Service Industry: Managerial Inefficiency or Environmental Inefficiency-Evidence from Telecommunication Industry in China. Ind. Econ. Res. 2018. [CrossRef]

21. Ran, Q.; Zhou, H. Research on Agricultural Total Factor Energy Efficiency under Environmental Constraints: Based on SBM-TOBIT Model. Econ. Probl. 2017, 103-109. [CrossRef]

22. Ma, F.; Wang, W.L.; Sun, Q.P.; Liu, F.; Li, X.D. Integrated Transport Efficiency and Its Spatial Convergence in China's Provinces: A Super-SBM DEA Model Considering Undesirable Outputs. Appl. Sci. 2018, 8, 1698. [CrossRef]

23. Xi, X.; Liang, J.; Yang, J. Does Local Fiscal Competition Improve the Efficiency of Public Infrastructure Investment? East China Econ. Manag. 2017, 31, 114-123. [CrossRef]

24. Ouyang, Y.; Zhang, G. Research on the Impact of Infrastructure Supply and Efficiency on "Made in China". Manag. World 2016, 97-109. [CrossRef]

25. Cheng, G. Data Envelopment Analysis: Methods and MaxDEA Software; Intellectual Property Publishing House: Beijing, China, 2014; pp. 120-181. ISBN 9787513027182.

26. Wang, J.; Xu, H. Estimation of Administrative Monopoly in Toll Road Industry and Corresponding Elimination Strategies. J. Xi'an Jiaotong Univ. (Soc. Sci.) 2012, 32, 75-80. [CrossRef]

27. The Core Task of the Supply-Side Reform of the Transportation Industry is De-Leveraging. Available online: http:/ /jjsb.cet.com.cn/show_480843.html (accessed on 1 December 2018). 
28. Wang, J.; Xiao, X.; Tang, Y. The Establishment of Regulatory Agencies and Their Operational Mechanisms in China's Monopoly Industries; Commercial Press: Beijing, China, 2008; pp. 236-243. ISBN 9787100058186.

29. Zhang, J. The Governance Efficiency of Debt Financing-A new Empirical Analysis Design. J. Shanxi Financ. Econ. Univ. 2006, 28, 117-121. [CrossRef]

30. Yang, J.; Yang, J. Administrative Monopoly Political, Patronage and the Extra-Cost of the State-Owned Firms. Econ. Res. J. 2015, 50, 50-61.

(C) 2019 by the authors. Licensee MDPI, Basel, Switzerland. This article is an open access article distributed under the terms and conditions of the Creative Commons Attribution (CC BY) license (http:/ / creativecommons.org/licenses/by/4.0/). 